OPEN ACCESS

Edited by:

Fatih Ozogul,

Çukurova University, Turkey

Reviewed by:

Anca loana Nicolau,

Dunarea de Jos University of Galati,

Romania

Chunlei Shi.

Shanghai Jiao Tong University, China

${ }^{*}$ Correspondence: Jenny Schelin jenny.schelin@tmb.lth.se

Specialty section: This article was submitted to

Food Microbiology,

a section of the journal

Frontiers in Microbiology

Received: 06 December 2018

Accepted: 27 May 2019

Published: 12 June 2019

Citation:

Zeaki N, Johler S, Skandamis PN and Schelin J (2019) The Role of Regulatory Mechanisms and Environmental Parameters in Staphylococcal Food Poisoning and Resulting Challenges to Risk

Assessment.

Front. Microbiol. 10:1307. doi: 10.3389/fmicb.2019.01307

\section{The Role of Regulatory Mechanisms and Environmental Parameters in Staphylococcal Food Poisoning and Resulting Challenges to Risk Assessment}

\author{
Nikoleta Zeaki', Sophia Johler², Panagiotis N. Skandamis ${ }^{3}$ and Jenny Schelin ${ }^{1 *}$ \\ ' Division of Applied Microbiology, Department of Chemistry, Lund University, Lund, Sweden, ${ }^{2}$ Institute for Food Safety \\ and Hygiene, University of Zurich, Zurich, Switzerland, ${ }^{3}$ Laboratory of Food Quality Control and Hygiene, Department \\ of Food Science and Human Nutrition, Agricultural University of Athens, Athens, Greece
}

Prevention, prediction, control, and handling of bacterial foodborne diseases - an ongoing, serious, and costly concern worldwide - are continually facing a wide array of difficulties. Not the least due to that food matrices, highly variable and complex, can impact virulence expression in diverse and unpredictable ways. This review aims to present a comprehensive overview of challenges related to the presence of enterotoxigenic Staphylococcus aureus in the food production chain. It focuses on characteristics, expression, and regulation of the highly stable staphylococcal enterotoxins and in particular staphylococcal enterotoxin A (SEA). Together with the robustness of the pathogen under diverse environmental conditions and the range of possible entry routes into the food chain, this poses some of the biggest challenges in the control of SFP. Furthermore, the emergence of new enterotoxins, found to be connected with SFP, brings new questions around their regulatory mechanisms and expression in different food environments. The appearance of increasing amounts of antibiotic resistant strains found in food is also highlighted. Finally, potentials and limitations of implementing existing risk assessment models are discussed. Various quantitative microbial risk assessment approaches have attempted to quantify the growth of the bacterium and production of disease causing levels of toxin under various food chain and domestic food handling scenarios. This requires employment of predictive modeling tools, quantifying the spatiotemporal population dynamics of $S$. aureus in response to intrinsic and extrinsic food properties. In this context, the armory of predictive modeling employs both kinetic and probabilistic models to estimate the levels that potentiate toxin production, the time needed to reach that levels, and overall, the likelihood of toxin production. Following risk assessment, the main challenge to mitigate the risk of $S$. aureus intoxication is first to prevent growth of the organism and then to hamper the production of enterotoxins, or at least prevent the accumulation of high levels (e.g., >10-20 ng) in food. The necessity for continued studies indeed becomes apparent based on the challenges to understand, control, and predict 
enterotoxin production in relation to the food environment. Different types of food, preservatives, processing, and packaging conditions; regulatory networks; and different staphylococcal enterotoxin-producing $S$. aureus strains need to be further explored to obtain more complete knowledge about the virulence of this intriguing pathogen.

Keywords: staphylococcal food poisoning, enterotoxins, SEA, regulatory mechanisms, environmental factors, food supply chain, predictive modeling, QMRA

\section{CONTROL AND MANAGEMENT OF STAPHYLOCOCCAL FOOD POISONING - CHALLENGES STILL SEEKING SOLUTIONS}

Foodborne diseases have been, and remain, a major global challenge in public health and economic development, with increasing numbers of incidents recorded in many countries worldwide. The WHO study on the global burden of foodborne disease estimates that 31 foodborne hazards cause 600 million illnesses and 420,000 deaths (WHO, 2015). Efforts are being made by all parties throughout the entire food chain to prevent, detect, and manage hazards resulting from the presence of foodborne pathogens. Steady changes in consumers' eating patterns and preferences along with increasing health concerns and environmental awareness have led to a continuous and growing demand for, e.g., ready-to-eat meals, minimally processed foods, and local products (Lupien, 2007; Lappo et al., 2015). New challenges are thus relentlessly arising in the battle against foodborne diseases. This is particularly the case for minimally processed foods that provide favorable environments for most pathogenic bacteria, among them Staphylococcus aureus. Staphylococcal food poisoning (SFP) is a foodborne intoxication caused by staphylococcal enterotoxins (SEs) and not the bacteria themselves. Thus, the virulence of $S$. aureus as a foodborne pathogen depends on the amount of SEs formed.

Proof of the association of $S$. aureus with food poisoning was obtained in 1914 by Barber (1914) who demonstrated that food poisoning resulted from the consumption of unrefrigerated milk from a cow with staphylococcal mastitis. Dack et al. (1930) showed that a filterable toxin, later called enterotoxin, was the causative agent of SFP. Today, S. aureus is considered one of the most common pathogens causing food intoxication (Fetsch and Johler, 2018). In the United States, approximately 241,000 cases of foodborne illness were reported to have been caused by S. aureus between 2000 and 2008, placing the pathogen in the fifth place among those most commonly reported (Scallan et al., 2011). In the European Union (EU), SEs were reported to be the causes of $8 \%$ of foodborne outbreaks in 2016 , rendering bacterial toxins the third most common causative agent of outbreaks (EFSA, 2017). In other parts of the world, such as Australia, intoxication by $S$. aureus accounted for $1 \%$ of all confirmed and suspected foodborne outbreaks between January 2000 and March 2012 (Pillsbury et al., 2013) whereas in China it was reported in 2013 that $12.5 \%$ of all foodborne bacterial outbreaks were caused by S. aureus (Wang et al., 2017). S. aureus is found on the skin and mucous membranes of humans and other warm-blooded animals, and is widespread in the environment. It can enter the food chain through various routes, the most common being via raw materials, food handlers, or poor hygiene in food processing equipment (Hennekinne et al., 2012; Fisher et al., 2018). In the case of $S$. aureus, contamination during food preparation and processing, or during post-production, is regarded as the main sources of risk (Argudín et al., 2010; Hennekinne et al., 2010; Kadariya et al., 2014; Castro et al., 2016). Ready-to-eat foods containing meat products and dressings, which are handled and consumed without further treatment, have been implicated in a number of SFP outbreaks (Table 1). In the EU summary report 2016 (EFSA, 2017) on foodborne outbreaks, the main vehicle for SFP outbreaks was reported to be "mixed foods" with $31 \%$ followed by milk and milk products with $22 \%$, highlighting the impact of post-processing of foods on the development of the disease.

Staphylococcus aureus is able to grow and produce enterotoxins under a wide range of temperatures, $\mathrm{pH}$ values, water activity $\left(a_{\mathrm{w}}\right)$ levels, and sodium chloride concentrations (Le Loir et al., 2003; Paulin et al., 2012; Adams et al., 2016). This robustness of the pathogen in a wide range of environmental conditions broadens the diversity of foods in which S. aureus can grow and express virulence (Hennekinne et al., 2012; EFSA, 2017). Thus, any food product that can support the growth of $S$. aureus could pose a risk in terms of SFP. Additional post-production handling of the food could further increase the risk of disease due to $S$. aureus contamination. Identifying the risks associated with $S$. aureus in the food handling and production environment, such as breach of hygiene, is one of the most important factors in the control of SFP. However, the dissemination of the pathogen in nature, its robustness under diverse conditions, and the level of knowledge of people involved in food processing are only some of the challenges associated with this pathogen. To these must be added specific differences among $S$. aureus strains including the variation in SE expression and production levels, the different types of mobile genetic elements encoding the $s e$ genes, and the accompanying range of different regulatory mechanisms. As stated above, SFP leads to intoxication due to the ingestion of enterotoxins preformed in the food (Fetsch and Johler, 2018). SEs produced by S. aureus are resistant to most of the treatments that eliminate bacterial cells, such as heat treatment and low $\mathrm{pH}$, and can therefore be present in food even after processing. Their resistance to proteolytic enzymes also enables them to pass through the digestive tract unaffected, thus increasing the risk of illness (Le Loir et al., 2003). The key element in preventing SFP outbreaks is thus to control the production of enterotoxins. 
TABLE 1 | Examples of major SFP outbreaks.

\begin{tabular}{|c|c|c|c|c|}
\hline Implicated food & $n$ cases & Country & Year & References \\
\hline Raw milk cheese & 200 & United States & 1958 & Johnson et al. (1990) \\
\hline Chicken salad & 1300 & United States & 1968 & CDC (1968) \\
\hline Sausage rolls, ham sandwiches & 100 & United Kingdom & 1971 & Morris et al. (1972) \\
\hline Ham & 197 & Flight from Japan to Denmark & 1975 & Eisenberg et al. (1975) \\
\hline Dessert cream pastry & 215 & Caribbean cruise ship & 1983 & CDC (1983) \\
\hline Cheese (sheep's milk) & 27 & Scotland & 1984 & Bone et al. (1989) \\
\hline Dried lasagna & 50 & France, United Kingdom, Italy, Luxembourg & 1985 & Woolaway et al. (1986) \\
\hline $2 \%$ chocolate milk & $>1000$ & United States & 1985 & Evenson et al. (1988) \\
\hline Canned mushrooms & 102 & United States & 1989 & CDC (1989) \\
\hline Eclairs & 485 & Thailand & 1990 & Thaikruea et al. (1995) \\
\hline Precooked ham & 18 & United States & 1997 & CDC (1997) \\
\hline Chicken, roast beef, rice, and beans & 4000 & Brazil & 1998 & Do Carmo et al. (2004) \\
\hline Low-fat milk & 13,420 & Japan & 2000 & Asao et al. (2003) \\
\hline Cheese (sheep's milk) & 104 & France & 2002 & Kérouanton et al. (2007) \\
\hline Potato snack & 100 & India & 2005 & Nema et al. (2007) \\
\hline Coconut pearls (Chinese dessert) & 17 & Île-de-France area, France & 2006 & Hennekinne et al. (2009) \\
\hline Milk, cacao milk, vanilla milk & 166 & Austria & 2007 & Schmid et al. (2009) \\
\hline Crepes & 75 & Japan & 2009 & Kitamoto et al. (2009) \\
\hline Raw milk cheese & 23 & France & 2009 & Ostyn et al. (2010) \\
\hline Raw milk cheese & 14 & Switzerland & 2014 & Johler et al. (2015) \\
\hline
\end{tabular}

Among the SEs and SE-like proteins produced by S. aureus, those usually associated with SFP are the five classical SEs: SEASEE (Wieneke et al., 1993; Cha et al., 2006; Kérouanton et al., 2007; Rajkovic, 2012). Staphylococcal enterotoxin A (SEA) is most frequently reported as the causative agent of SFP outbreaks ( $80 \%$ of cases), followed by SEB, SEC, and SED (Pinchuk et al., 2010; Hennekinne et al., 2012; Sospedra et al., 2013). The challenge in understanding and controlling the production of SEs lies in the complexity and diversity of the encoding genetic elements and regulation mechanisms. The se genes are carried on various genetic elements such as plasmids, bacteriophages, pathogenicity islands (SaPIs), and the enterotoxin gene cluster (egc) (Genigeorgis, 1989; Le Loir et al., 2003; Argudín et al., 2010; Hennekinne et al., 2012). Different regulatory mechanisms are involved in SE expression depending on the genetic element carrying the SE.

The mechanisms controlling SE production in $S$. aureus are numerous and include se gene promoter regions, multiple global regulators of virulence, such as the accessory gene regulator (agr), the staphylococcal accessory regulator (sar), the repressor of toxins (rot), the sigB factor, and the twocomponent system $S$. aureus exoprotein expression (sae), in addition to a cytoplasmic SEB form that controls SEB production (Gustafson and Wilkinson, 2005). Selected classical enterotoxins with respective regulatory mechanism/s/ are summarized in Table 2 and also well accompanied in Figure 1 in the review by Fisher et al. (2018) that gives an overview of the relationship between growth environment/condition, regulatory mechanisms, and type of SE (Fisher et al., 2018). Knowledge concerning the regulatory mechanism of a SE can therefore be of great value in the effective prevention of $S$. aureus intoxication, as the appropriate interventions may differ depending on the
SE-producing S. aureus strain. SEA and SED can be used to exemplify different mobile elements and different regulatory systems, as SEA is encoded by a bacteriophage, while SED is encoded by a plasmid. The latter is partly regulated by the agr system, a quorum sensing system that enables $S$. aureus to respond to cell density, and SED is thus mainly produced

TABLE 2 | Selected S. aureus enterotoxins regulated by Agr, SarA, $\sigma^{\mathrm{B}}$, Rot, and SaeRS.

\begin{tabular}{|c|c|c|c|c|c|c|}
\hline Enterotoxins & Agr & SarA & $\sigma^{\mathrm{B}}$ & Rot & SaeRS & References \\
\hline SEA & 0 & nd & 0 & $0 /-$ & nd & $\begin{array}{l}\text { Tremaine et al. } \\
\text { (1993), Tseng et al. } \\
\text { (2004), Kusch et al. } \\
\text { (2011), Sato'o et al. } \\
\text { (2015) }\end{array}$ \\
\hline SEB & $+/ 0$ & + & - & - & + & $\begin{array}{l}\text { Compagnone-Post } \\
\text { et al. (1991), } \\
\text { Regassa et al. } \\
\text { (1991), Schmidt } \\
\text { et al. (2004), Tseng } \\
\text { and Stewart (2005), } \\
\text { Kusch et al. (2011) }\end{array}$ \\
\hline SEC & + & + & + & nd & nd & $\begin{array}{l}\text { Chien et al. (1999), } \\
\text { Regassa et al. } \\
\text { (1991), Voyich et al. } \\
\text { (2009) }\end{array}$ \\
\hline SED & $+/ 0$ & + & - & - & nd & $\begin{array}{l}\text { Bayles and landolo } \\
\text { (1989), Tseng et al. } \\
\text { (2004), Sihto et al. } \\
(2015,2016 a)\end{array}$ \\
\hline SEE & nd & nd & nd & nd & nd & \\
\hline
\end{tabular}

+, activation; -, repression; 0 , no effect; nd, not determined. 

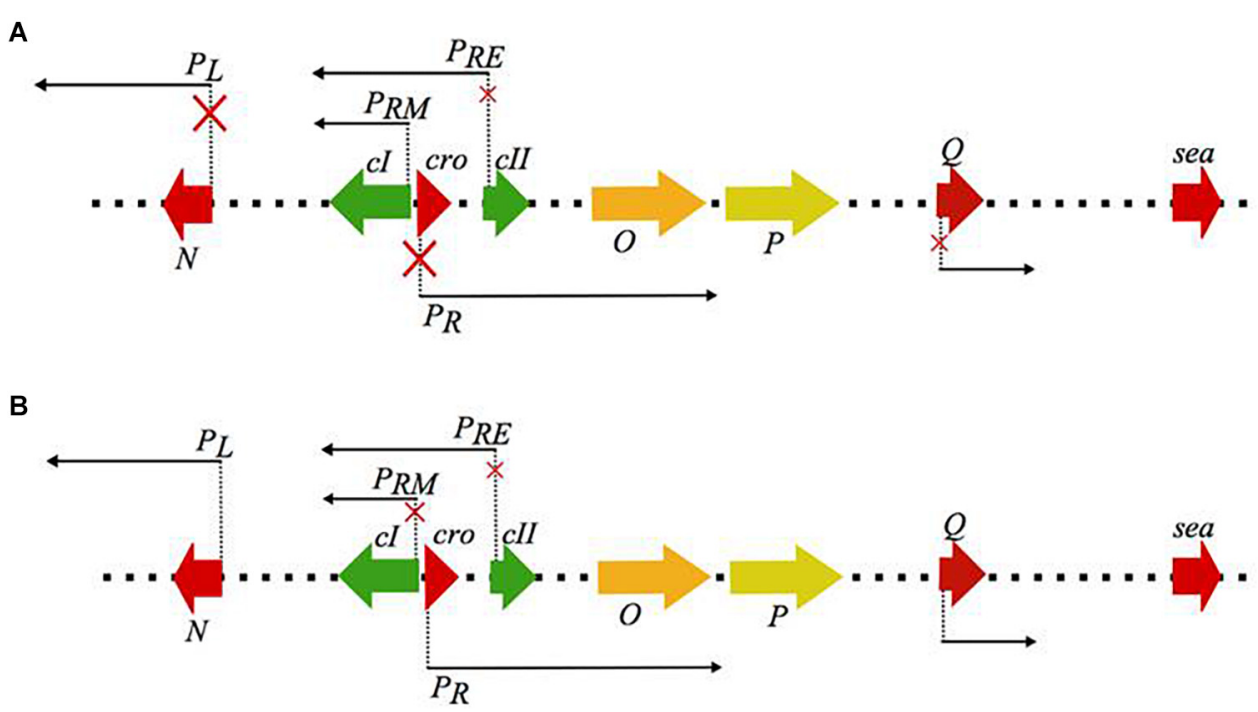

FIGURE 1 | Schematic representation of the regulatory events occurring during (A) lysogenic and (B) lytic mode of the $\lambda$ phage life cycle, that serves as the model for the closely related Siphoviridae genera. The red $\mathbf{x}$ on the promoter arrows indicate repression of transcription from the respective promoters. During the lysogenic mode $\mathrm{cl}$ autoregulates its expression through the $\mathrm{P}_{\mathrm{RM}}$ promoter while it represses the lytic promoters $P_{R}$ and $P_{L}$ which regulate the early ( $\mathrm{N}$, $\mathrm{O}$, $\mathrm{P}$ ) and the late lytic genes located downstream the $Q$ promoter, including the virulence genes, like the sea gene. Under the events that favor the lytic mode, $c /$ autoregulation from $\mathrm{P}_{\mathrm{RM}}$ seizes and transcription from the lytic promoters is initiated. The regulatory protein of the lytic mode is cro, which represses the expression of $c / l$ and therefore re-establishment of the $\mathrm{cl}$ expression (figure modified from Oppenheim et al., 2005).

during the transition from the exponential to the stationary growth phase of the microorganism (Schelin et al., 2011). The regulation of SEA, however, has been linked to the life cycle of the bacteriophages carrying the sea gene, with SEA production being the highest during the exponential growth phase, at the peak of replication (Derzelle et al., 2009; Schelin et al., 2011). Furthermore, these regulatory mechanisms are affected in different ways by the environmental conditions in a food product, such as salt content, water activity, and pH (Schelin et al., 2017). This can have a further impact on the production of the respective enterotoxins, making them difficult to control.

The location of the se genes on mobile genetic elements presents an additional challenge in SFP control, as it supports horizontal gene transfer between different $S$. aureus strains, and therefore the dissemination of se genes (Hennekinne et al., 2012). The transfer of genetic elements in S. aureus has contributed to strain variability and enhanced virulence, as $S$. aureus strains usually carry more than one se gene (Becker et al., 2003). These evolutionary trends in $S$. aureus call for constant research to identify potentially new strains and to understand their behavior and virulence expression with regard to SFP.

\section{A GLIMPSE OF S. AUREUS ENTRY ROUTES INTO THE FOOD CHAIN}

The diversity of food products implicated in SFP is apparent from documented outbreaks (Table 1). The robustness of S. aureus under a wide range of environmental conditions should be considered a virulence parameter, making it difficult to predict the general behavior of the pathogen in various food matrices under different environmental conditions. The series of events in an SFP outbreak typically include the following: (i) the presence of the pathogen in raw materials or the food handler(s), (ii) contamination of the food, for example, through processing equipment or through the food preparer, (iii) inappropriate storage conditions and/or inadequate temperature control that allow for bacterial growth and enterotoxin production, and (iv) ingestion of contaminated food containing a sufficient amount of SE to trigger symptoms of the disease. The majority of welldocumented outbreaks indicate that the most common means of contamination in cases of SFP are poor hygiene practices during the processing, cooking, and distribution of food products. Inadequate cooling of food products is the main cause of $S$. aureus growth leading to disease (Pereira et al., 1996; Asao et al., 2003; Schmid et al., 2009; Hennekinne et al., 2012).

One of the first well-documented SFP outbreaks was reported by Denison (1936) and involved the consumption of contaminated cream puffs by high school students. In this case, the source of contamination was not actually identified. In more recent years, a large-scale SFP outbreak affected as many as 13,420 individuals, and involved the consumption of dairy products that contained SEA (Asao et al., 2003). From the investigation of this outbreak it was found that the source of contamination was the powdered skim milk used to produce the dairy products involved in the outbreak. The most interesting factor in this case was that the contaminated products had been heat-treated, in some cases as much as three times, at $130^{\circ} \mathrm{C}$ for 2 or $4 \mathrm{~s}$, and bacterial cells of $S$. aureus were completely eliminated. SEA retained, however, both its immunological and emetic activity and led to food poisoning (Asao et al., 2003). Besides the classical types of food products associated with 
S. aureus contamination an example of a more recent study investigated the prevalence on various retail vegetables in China between 2011 and 2016 (Wu et al., 2018). Although the levels of S. aureus were moderate, it was found in $5.73 \%$ of the samples and lettuce was the most common vegetable. In addition to the conventional entry routes connected with production and processing environments, the global trade and especially the illegal transportation of food across borders have also been found to contribute to the transmission of S. aureus (Müller et al., 2016; Rodriguez-Lazaro et al., 2017). Another alarming concern is that not only enterotoxigenic but also methicillin-resistant $S$. aureus (MRSA) strains are increasingly being isolated from a variety of meat and dairy-based products as well as ready-to-eat foods indicating that the food chain is one additional and alternative reservoir as well as transmission route for antimicrobial resistant bacteria (Sergelidis and Angelidis, 2017; Islam et al., 2019; Wu et al., 2019).

Staphylococcal enterotoxin A is one of the more extensively studied SEs, mainly due to the fact that it accounts for $80 \%$ of reported SFP cases. Its worldwide predominance has been extensively documented (Argudín et al., 2010). In a study of 359 SFP outbreaks in the United Kingdom that took place between 1969 and 1990, it was shown that 79\% of the S. aureus strains involved produced SEA (Wieneke et al., 1993). SEA was the only enterotoxin detected in $56.9 \%$ of the outbreaks, while in a few cases it was detected together with SED, SEB, and SEC, or with SEB and SED. The sources implicated included meat, poultry, and products thereof, especially ham and chicken. The sea gene was also the predominant enterotoxin gene detected in dairy products implicated in SFP outbreaks in Brazil (Veras et al., 2008). SEA was the most frequent causative agent in $69.7 \%$ of SFP outbreaks in France between 1981 and 2002 (Kérouanton et al., 2007). A challenging aspect of this high prevalence with regard to controlling SFP intoxication is that SEA is one of the few SEs whose regulation is not dependent on the agr system. A number of studies have investigated the expression of the sea gene in connection with alternative regulatory mechanisms, in order to understand the conditions under which the enterotoxin is produced. In the following section, SEA will be used as a characteristic example of the challenges from different genetic backbones; the regulatory mechanisms; and environmental stress responses to the robustness, growth behavior, and strain variations associated with SE production by S. aureus leading to SFP.

\section{EXPRESSION AND PRODUCTION OF ENTEROTOXINS IN FOOD}

\section{Staphylococcal Enterotoxin A}

The sea gene encoding for SEA is located on the genome of a polymorphic family of lysogenic bacteriophages, the Siphoviridae family. Localization of the sea gene on these phages has been found to affect its expression and the production of SEA, creating variations between the SEA-producing strains and the virulence these can express when found in food (Betley and Mekalanos, 1985; Borst and Betley, 1994; Zeaki et al., 2015a).
To date, five $S$. aureus bacteriophages are known to carry the sea gene, namely: ФSa3ms, ФSa3mw, Ф252B, ФNM3, and ФMU50A (Goerke et al., 2009; Deghorain and Van Melderen, 2012). These are temperate bacteriophages and are thus able to establish a permanent symbiosis with their bacterial host, known as lysogeny. Lysogenic bacteria (or "lysogens") are cells where the phage genome has integrated into the bacterial chromosome and will be steadily transmitted to the bacterial progeny as a prophage (Thieffry and Thomas, 1995). In this state, the lysogenic bacterium will inherit the characteristics attributed to phage genes, such as resistance to antimicrobial substances and virulence expression.

In addition to inheriting phage genes, the symbiosis of S. aureus with the sea-carrying phages leads to another challenge, that of strain variation regarding virulence. It has been established, through a number of studies, that the SEA-producing $S$. aureus strains can be categorized into high and low SEA producers, depending on the sea-carrying prophage they harbor (Borst and Betley, 1994; Wallin-Carlquist et al., 2010a; Cao et al., 2012). Wallin-Carlquist et al. (2010a) showed that there are two sea variants: $s e a_{1}$ and $s e a_{2}$; the high-SEA-producing strains carried $s e a_{1}$, while $s e a_{2}$ was found in the low-SEA-producing strains. It could therefore be proposed that the SEA-producing strains bearing the $s e a_{1}$ gene variant are more likely to cause SFP than those bearing the $\mathrm{sea}_{2}$ gene variant.

The state of lysogeny, although very stable, can be disrupted by certain environmental conditions (i.e., the presence of weak acids, high $\mathrm{NaCl}$ concentration, UV irradiation, and DNA damage by chemical agents), and in such cases, the lytic response is initiated by the phage; a process known as prophage induction (Figure 1; Oppenheim et al., 2005). Prophage induction has been found to increase the amount of SEA produced by some SEA-producing strains, and thus increases the probability of SFP (Figure 2).

In 1994, Borst and Betley identified an endogenous promoter responsible for sea mRNA expression, immediately upstream of the gene. Cao et al. (2012) demonstrated the differences between the designated groups of high- and low-SEA-producing strains regarding the expression of sea mRNA. Specifically, they showed that relative quantification of sea mRNA originating from the endogenous sea promoter (designated $\mathrm{P}_{1}$ ) was only possible in the high-SEA-producing strains, i.e., those bearing the sea gene variant. Furthermore, it was shown that some of these strains had the ability to produce increased amounts of SEA when cultures were subjected to prophage induction using mitomycin C. In these strains, a second sea transcript was detected and quantified originating from a latent promoter $\left(\mathrm{P}_{2}\right)$ located upstream of the endogenous sea promoter $\left(\mathrm{P}_{1}\right)$ (Sumby and Waldor, 2003; Cao et al., 2012). The high-SEA-producing group was thus divided into two sub-groups, the inducible high-SEA producers, for which the expression of two sea transcripts and higher SEA levels was observed after induction, and the non-inducible highSEA producers, for which no effects on sea transcription and translation was seen (Cao et al., 2012).

Apart from the impact on sea mRNA expression, prophage induction also causes changes in the number of copies of the circular, replicative form (RF) of the phage genome in the cell. At a particular point during the life cycle of the phage, the 


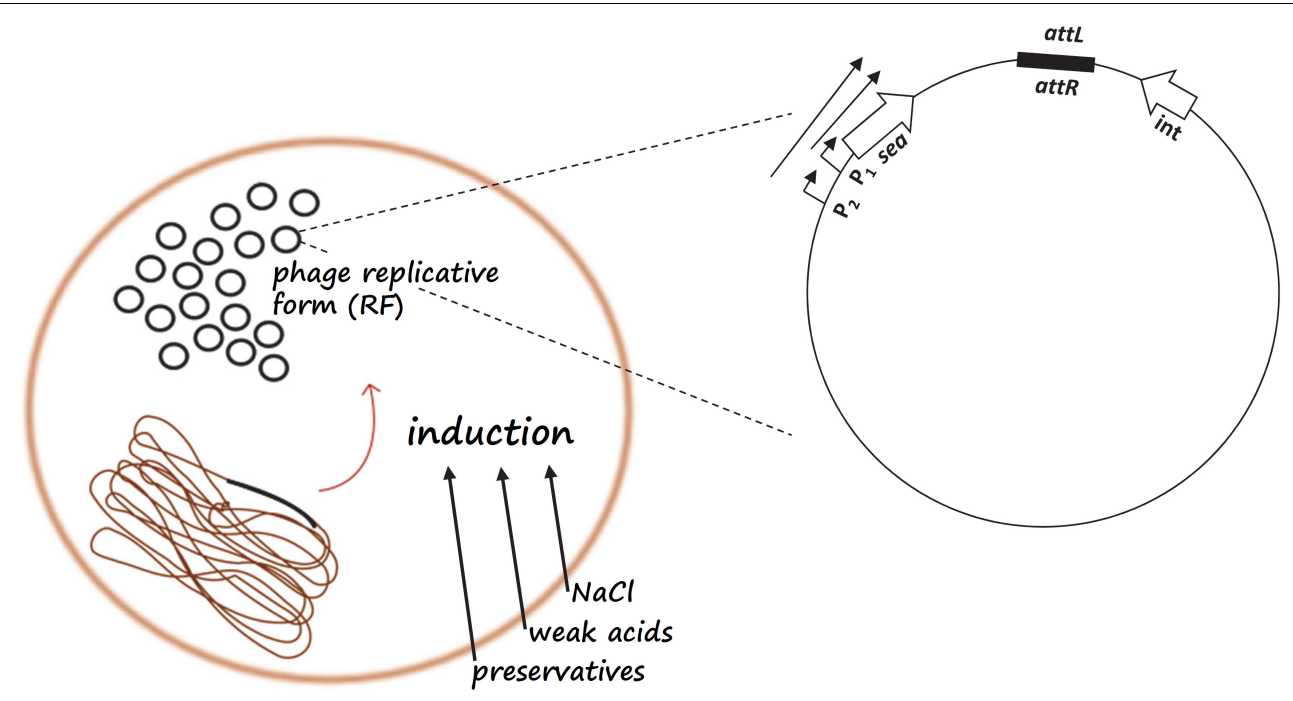

FIGURE 2 | Schematic representation of the sea gene regulatory mechanism. Food parameters such as $\mathrm{NaCl}$, weak acids, and preservatives may lead to prophage induction and replication of the circular, replicative form (RF) of the phage genome, resulting in an increase in RF copies in the cell. Prophage induction will initiate transcription from the latent promoter $\mathrm{P}_{2}$ resulting in the production of a longer sea transcript in addition to the sea transcript from the endogenous $\mathrm{P}_{1}$ promoter.

host cell cytoplasm will contain a considerably higher number of RF copies and, consequently, of phage-associated genes available for potential transcription. Therefore, in the case of the sea-carrying phages, prophage induction and phage genome replication increase the sea gene pool in the cell, and the amount of sea mRNA produced, possibly enhancing SEA production (Figure 2). This hypothesis was investigated in a study by Zeaki et al. (2015a), where the RF copies were quantified before and after prophage induction. From this analysis it was demonstrated that the inducible high-SEA-producing strains exhibited high numbers of RF copies after prophage induction and increased SEA levels, in contrast to the non-inducible strains.

The findings demonstrating all the dimensions through which the life cycle of the sea-carrying phages regulates SEA production were generated under laboratory conditions. This highly complex regulatory mechanism has an immediate impact on the virulence of $S$. aureus and SFP, since several parameters encountered in food or during food production could lead to prophage induction, and thus to high SEA levels. To elucidate the increased risk of SFP due to SEA production in the food environment, studies on food matrices and/or including food parameters, such as high $\mathrm{NaCl}$ concentration and/or weak acids, should be performed.

\section{SEA Production in Food}

Food provides a rich source of nutrients for all types of bacteria. Guidelines for good manufacturing practices and controls for food safety have been developed and were adopted by the food industry to minimize the contamination of food products. Various preservation methods are employed to further prevent the growth of pathogenic bacteria due to potential postproduction contamination (Adams et al., 2016). These methods make the environment less favorable for bacterial growth, by reducing the oxygen level, the $\mathrm{pH}$, and water activity value.
However, in the case of $S$. aureus and SEA production, adverse conditions in the food environment could lead to prophage induction and increased SEA production.

A number of studies have investigated food parameters affecting the growth of $S$. aureus and SEA production (Genigeorgis, 1989; Belay and Rasooly, 2002; Wallin-Carlquist et al., 2010a,b; Rosengren et al., 2013; Sabike et al., 2014; Zeaki et al., 2014, 2015b; Hu et al., 2018). The generally accepted limits for SE production are temperatures between 10 and $48^{\circ} \mathrm{C}$, a $\mathrm{pH}$ range of $4-9.6$, and $\mathrm{NaCl}$ concentrations of 0 $10 \%$. However, most studies have focused on rather extreme parameters that inhibit either the growth of the pathogen and/or SE production, rather than investigating a range typically found during food production and preservation. In addition, they largely omitted effects on a regulatory level. The impact of regulatory mechanisms on the production of SEs can be significant and can vary between $S$. aureus strains producing the same enterotoxin. In a study of Wallin-Carlquist et al. (2010a), it was shown that acetic acid increased the expression of the sea gene at $\mathrm{pH}$ 6.0, a pH level at which increased copy numbers of the gene were also detected. Zeaki et al. (2015b) observed a similar effect on the copy number of sea and the sea-carrying phage genome, when $2 \% \mathrm{NaCl}$ was added to the growth medium. In both studies, however, the increase in expression and the number of copies of the gene was not translated into increased SEA levels. This could be attributed to inhibition of the biosynthesis of SEA or its secretion from the $S$. aureus cell due, for example, to the accumulation of compatible solutes such as proline, glycine, and betaine by the cell under osmotic stress, which are also essential for SEA synthesis. However, these amino acids could be available from alternative sources in a food environment, and thus SEA synthesis could re-establish and reach levels causing SFP. The above example highlights the importance of considering the composition of a food product when deciding on preservation 
treatments for the effective inhibition of SE production. It has been shown, for example, that the addition of glucose reduces enterotoxin production due to catabolic repression and as a consequence of $\mathrm{pH}$ reduction due to the fermentation of carbohydrates (Jarvis et al., 1975; Smith et al., 1986; Hallis et al., 1991; Weinrick et al., 2004).

Wallin-Carlquist et al. (2010b) investigated the growth of $S$. aureus and the production of SEA in four different processed pork products (boiled ham, hot-smoked ham, Serrano ham, and black pepper salami). The different food environments were found to have different effects. Cell growth and SEA production at levels likely to cause SFP were observed in the boiled and hot-smoked ham early in the incubation period, while in the harsher environments (i.e., high salt and fat content, low water activity, low $\mathrm{pH}$, presence of competing microbiota, and immobilized growth) of Serrano ham and black pepper salami, growth and SEA production were observed after 5 days of incubation in the Serrano ham, and not at all in the black pepper salami. Interestingly, sea expression was detected throughout the incubation period, in contrast to what has been observed in broth, in which sea expression peaks at the transition from the exponential to the stationary growth phase, and then declines (Borst and Betley, 1993; Derzelle et al., 2009; Wallin-Carlquist et al., 2010a,b). These observations evidence the variability of SE expression depending on the product of interest, and the differences in sea gene regulation between food matrices and laboratory conditions.

In a more recent study by Zeaki et al. (2014) on pork sausages, the inter-strain variability of $S$. aureus with respect to growth, sea expression, and SEA production was investigated. The pork sausages were inoculated with three $S$. aureus strains, previously known to produce different amounts of SEA when grown under the effect of mitomycin $\mathrm{C}$, despite their similar growth patterns. The temperature $\left(15^{\circ} \mathrm{C}\right)$ used during filling of the meat paste into the skin in sausage production was used for incubation, as this also represents an inadequate refrigeration temperature. It was found that although all three strains exhibited very similar growth patterns during the 14 days of incubation, the levels of SEA produced differed considerably. Two of the strains previously characterized as high-SEA producers produced SEA levels in the pork sausage environment high enough to cause food intoxication, while the low-SEA-producing strain did not. In addition, one of the two high-SEA producers yielded significantly higher SEA levels than the other high-SEAproducing strain. These two strains had previously been found to produce similar levels of SEA in a laboratory experiment in broth. This observation is related to prophage induction and indicates that some food parameters may trigger this process, increasing S. aureus virulence.

The importance of the findings presented above becomes clear when considering the methods used to ensure the safety of a food product for consumption. The guidelines for microbial safety of food products are based on acceptable pathogen counts in a critical food portion (ECDC, 2005). In the guidelines in the US Food and Drug Administration's "Bad Bug Book," the level of $S$. aureus producing enterotoxins that could cause intoxication is defined as $\approx 10^{5} \mathrm{cfu} / \mathrm{g}$. Thus, SFP risk assessment is based on the level of $S$. aureus detected in the final product. Yet, as was shown in the study by Zeaki et al. (2014), SEA production varied between the studied strains, despite the fact that the growth patterns of the microorganisms were similar. Strain-specific variation has furthermore been demonstrated in several other studies in regard to different toxins and regulatory mechanisms (Blevins et al., 2002; Cassat et al., 2006; Sihto et al., 2016b; Susilo et al., 2017). Therefore, current methods of evaluating the safety of food products with regard to $S$. aureus are inadequate and should be complemented with more information regarding the virulence and diversity of individual strains and SEs.

\section{Other Classical Enterotoxins}

Staphylococcal enterotoxin A presents a distinctive complexity in its regulatory system compared to the majority of SEs, in addition to being the one most often implicated in SFP outbreaks. Nevertheless, SEs such as SEB, SEC, and SED have been recorded as sources of SFP cases, with SEB being the second most common cause after SEA (10\%) (Pinchuk et al., 2010). Therefore, a deeper understanding of their behavior when found in food is essential. In fact, comparative knowledge of the regulatory mechanisms governing the expression and production of SFP-relevant SEs would be of great value, for example, for risk assessment models on $S$. aureus virulence.

The response of $S$. aureus to environmental changes is controlled by a highly complex network of intertwined regulatory pathways, including quorum-sensing and other two-component systems as well as trans-acting regulatory proteins (Fisher et al., 2018; Poupel et al., 2018). SEB, SEC, and SED, in contrast to SEA, are regulated by the agr quorum-sensing system to different extents (Table 2). The latter has been extensively studied under laboratory conditions regarding its up- and down-regulation by parameters such us sodium chloride, glucose, weak organic acids, and other. Several trans-activating regulators such as $\sigma^{\mathrm{B}}$, SrrAB, or the Sar family of regulatory proteins also influence agr expression (Fisher et al., 2018). Some studies have further looked into the impact of the up- and down-regulation of agr on the production of SEs. For example, in the study of Regassa et al. (1991), the effects of glucose and $\mathrm{pH}$ on the expression of agr and sec were evaluated. It was revealed that agr expression decreased dramatically under the presence of glucose and when the $\mathrm{pH}$ was 5.5. Similarly, glucose reduced the levels of sec mRNA and its impact was further enhanced when $\mathrm{pH}$ was 5.5 or non-maintained. In another study, on SED expression under glucose (30\%) and lactic acid stress ( $\mathrm{pH}$ 6.0), it was shown that glucose stress decreased the expression of SED, while lactic acid stress had no significant impact (Sihto et al., 2016b). When six different organic acids were investigated on their impact on S. aureus growth (strains FRI-100, S6, FRI-137, and FRI472) and SE (SEA, SEB, SEC, and SED) production, it was revealed that their effect varied between strains and type of SE. For example, SEA was decreased in the presence of most acids. However when $S$. aureus FRI-100 was grown with pyruvic or propionic acid, its concentration increased. SEB was the enterotoxin the least affected by the presence of all acids. In addition, for strain S6, though its growth was the most inhibited, SEB levels were distinctly high with all acids investigated, 
higher than what could be expected when considering growth (Domenech et al., 1992).

The presented examples provide useful information for the behavior of $S$. aureus when grown under the effect of compounds used in food production. However, little knowledge exists, also in the case of the $a g r$-regulated SEs, on their response in food. Moreover, the level to which agr regulates the production of these SEs has not been completely identified and other potential mechanisms affecting these SEs are yet to be discovered.

The existing food studies provide interesting observations on the impact of the food environment on SE production. In a study by Alibayov et al. (2015) on SEC expression and production in four different meat products (chicken ham, pork ham, pepper beef salami, and turkey ham), significant differences were observed on sec expression among these products, though growth followed a similar pattern. The differences were attributed both to the differences in fat content between the products, as well as the harshness of each of them $(\mathrm{NaCl}$ concentration and $\mathrm{pH})$. When the effect of $\mathrm{NaCl}$ on sed expression was investigated by Sihto et al. (2015), a decrease was observed in the expression of the gene in the studied strains. One $S$. aureus strain, however, exhibited a trend toward increased sed expression, suggesting possible induction of sed expression by $\mathrm{NaCl}$ stress. Briefly, studies in milk on SEC have demonstrated substantial reduction of both expression and production of the enterotoxin (Valihrach et al., 2013). In the same study, differences were observed between the expression profiles of sec and other se genes under the same conditions.

\section{Newly Described Enterotoxins}

While the role of newly described SEs in SFP has been controversially discussed, evidence is strongly suggesting a contribution to SFP (for a comprehensive review, see Fisher et al., 2018). Still, data on the expression of newer SEs and regulatory elements involved are scarce and expression in the food matrix is largely unknown. Transcription of the phageencoded newer enterotoxins sek and seq is linked to the phage's life cycle and can be induced by mitomycin C (Sumby and Waldor, 2003). Kusch et al. (2011) showed that transcription of sek and seq is not affected by loss of SaeS and $\sigma^{\mathrm{B}}$ in the strains COL and MA19, whereas expression of the egc encoded newer enterotoxins (seg, sei, sem, sen, seo, seu) depends of $\sigma^{\mathrm{B}}$. Expression of the transposon-associated seh has been suggested to be Agr independent (Lis et al., 2012) and controlled by Rot, SaeR, and SarR homologs (Sato'o et al., 2015) as well as $\sigma^{\mathrm{B}}$ (Kusch et al., 2011). Sato'o et al. (2015) suggested that Rot binds directly to the seh promoter, thus leading to seh mRNA transcription. They also reported that when comparing SE production in laboratory media and meat product using ELISA, many SEs could only be detected in laboratory medium and not in the food matrix, including SEB, SEC, SED, and the newer enterotoxins SEG and SEI (Sato'o et al., 2015). Expression of selj was suggested to be Agr-independent (Zhang et al., 1998). A recent study by Schubert et al. (2017) showed that the production of SER in meat juice exceeded SER production of the same strains in milk by a factor of between 15 and 269. Their findings also show pronounced strain-specific variation in ser expression.

\section{CHALLENGES AND POSSIBILITIES USING RISK ASSESSMENT TO PREDICT ENTEROTOXIN PRODUCTION AND STAPHYLOCOCCAL FOOD POISONING}

Describing and quantifying bacterial growth in food environments are rather complex - as complex is the response of the bacteria in the food matrix itself. Furthermore, changes in food production methods and pathogen evolution create a need for continuous research on microbial risk assessment. Understanding the genetic mechanisms that regulate the phenotypic responses of bacteria, and incorporating this knowledge into existing predictive models, will greatly improve hazard identification and pathogen control. Risk assessment associated with SFP has another degree of complexity due to the necessity of assessing SE production, and not just the presence or absence of the organism. This means that the strain of $S$. aureus, the type and amount of SE produced, and the possible correlation between growth and SE production must be evaluated. The potential for intoxicating amounts of SE to be present in a food product, even in the absence of viable $S$. aureus cells, should also be considered when assessing the risk posed by this organism (Cretenet et al., 2011).

A number of studies have been carried out, with focus on assessment of $S$. aureus risk of growth and toxin production in various products, including milk, unripened raw-milk cheese, home-cooked foods, and cream-filled bakery products (Lindqvist et al., 2002; Stewart et al., 2003; Taulo et al., 2008; Heidinger et al., 2009; Kim et al., 2009). As one of the major components of risk assessment is the exposure assessment, the use of predictive models is an essential tool for estimating the spatiotemporal changes of $S$. aureus population in the food chain, the attainment of toxin producing levels in target foods, and the amounts of toxins present in foods at the time of consumption. The existing predictive models are capable of simulating dynamics of cell populations and toxin production over time, in response to the main factors, controlling microbial growth, such as temperature, $\mathrm{pH}$, and water activity. Both kinetic and probabilistic models are available, as detailed in the following lines, some also being readily available in predictive modeling databases, such as ComBase. Nonetheless, the polynomial models of ComBase are generic models trained on responses of multiple $S$. aureus strains to temperature $\left(7.5-30^{\circ} \mathrm{C}\right), \mathrm{pH}(4.4-7.0)$, and $a_{\mathrm{w}}(0.907-1)$ in broth. As a counteract to the limitations of broth-based models, growth simulations via the above predictive modeling platforms enable the users to assess the impact of variability in population dynamics, thereby assessing the stochastic response of microorganisms, which is an important feature for exposure assessment.

Regarding the food-specific models, Fujikawa and Morozumi (2006) developed a model describing the rate of SEA production on the basis that the enterotoxin is formed when $S$. aureus levels are greater than $6.5 \log \mathrm{cfu} \mathrm{ml} \mathrm{m}^{-1}$, and that the relationship between SEA production and growth is linear in the temperature range $15-32^{\circ} \mathrm{C}$. In a study by Valero et al. (2009), the influence of temperature, $\mathrm{pH}$, and water activity on the growth of $S$. aureus 
was evaluated and fitted in a growth/no growth model. Lindqvist et al. (2002) used predictive modeling and survey data in combination with probabilistic modeling to simulate the levels of $S$. aureus at the time of consumption of unripened cheese made from raw milk. In this way, they evaluated the risk associated with consumption of this cheese and found that the initial $S$. aureus population, $\mathrm{pH}$, and storage time were the main risk factors. Barker and Goméz-Tomé (2013) took risk assessment one step further and developed a probabilistic model for the representation of the risks that arise in pasteurized milk from the presence of $S$. aureus, and particularly SEs, during the entire production chain. Specifically, they implemented probabilistic analysis with a Bayesian belief network, and in that way introduced the concept of biotraceability. Thus, the model developed by Barker and Goméz-Tomé (2013) allowed the identification of the main hazard sources. This in turn allowed for conclusions on where pre-emptive action should be taken in the milk production process to increase its efficiency and safety (Barker and Goméz-Tomé, 2013).

A limitation of the models developed to date, such as those described above, is the fact that the risk is assessed based on predicted levels of $S$. aureus that have been associated with enterotoxin production, rather than predicted enterotoxin levels in the final product, or the actual dose-response. Moreover, the information usually included in these models is generic, i.e., it does not distinguish between the different types of enterotoxins and their gene regulatory mechanisms. The latter is a key challenge for assessing the severity of the disease and for characterizing the impact of the food (micro)-environment and storage conditions on the ability of $S$. aureus to produce toxin. In this context, the marginal conditions allowing production of SEA are different from those that permit growth of $S$. aureus (Borneman et al., 2009; Ding et al., 2016), whereas toxin production may also be induced by severe stresses (Cao et al., 2012). Nonetheless, despite the existing preliminary indications, whether and how frequently these types of stress are associated with food environments requires further investigation (Zeaki et al., 2014, 2015b). Overall, the aforementioned evidence suggests that the toxin producing $S$. aureus levels are practically variable and a generic threshold cannot be reliably set. Usually in quantitative microbial risk assessment (QMRA) approaches, the prediction of $S$. aureus growth by the time of consumption is linked to the correlation between levels of $S$. aureus and toxin and the assumption of a minimum toxin amount of 20-50 ng for the occurrence of intoxication symptoms, in order to assess the risk of intoxication (Kim et al., 2009).

Many of the existing studies highlight the need for more information regarding the dynamics of $S$. aureus growth in relation to gene expression and enterotoxin production, the impact of different food environments on gene regulation, and relevant dose-response data, to improve risk assessment (Lindqvist et al., 2002; Fujikawa and Morozumi, 2006; Schelin et al., 2011; Barker and Goméz-Tomé, 2013). Rosengren et al. (2010) addressed the knowledge gaps in risk assessment associated with $S$. aureus in fresh and short-time ripened cheeses in Sweden. The areas where gaps were identified included producers' practices at farm dairies, the properties and the virulence of various $S$. aureus strains, the sources of $S$. aureus, and the impact of pasteurization and starter cultures on $S$. aureus levels. Given that $S$. aureus is considered a rather "poor" competitor, predictive models have also quantified the competitive effect of starter cultures (e.g., lactic acid bacteria) on the growth of $S$. aureus, in response to temperature (Le Marc et al., 2009). The model was based on the so-called "Jameson effect," which practically describes the growth cessation of the weaker organism in a binary culture, when the competitor reaches a threshold population, which is higher than the other organisms.

The complexity of SE production and the network of synergistic signals that regulate enterotoxin expression highlight the need for physiology-based, or even genotype-specific $S$. aureus risk assessments, thus, paving the way of increasingly integrating -omics in QMRA. These issues are further discussed in the following lines. The $S$. aureus strain and, in the case of phage-encoded enterotoxin genes such as sea, the respective seacarrying phage are critical parameters influencing the relevance of $S$. aureus as a potential etiological agent in an SFP outbreak and need to be taken in account for risk assessment. Moreover, the effect of the environment on enterotoxin expression should be considered when assessing the risk of SFP. Various studies evidence the limitation on the reliability of risk assessment based on the assumption that cell growth and enterotoxin production are related (Marta et al., 2011; Zeaki et al., 2014; Schelin et al., 2017). In addition to what was mentioned above for the probability of toxin production it is also the $S$. aureus growth rate that follows different patterns from those of enterotoxin production, depending on growth conditions and strain. For SEA, more studies, including different $S$. aureus food isolates carrying different Siphoviridae bacteriophages could further improve our knowledge concerning the regulation of expression. The schematic representation of the events regulating prophage induction in the study by Zeaki et al. (2015a) could serve as a template into which more information on sea gene expression could be incorporated to create a model including the factors that should be considered during risk assessment for SFP (Figure 2). Furthermore, additional data on the growth of $S$. aureus and SEA production on various food matrices could improve quantitative models for more accurate estimates of SEA production.

Another challenge that remains to be overcome when assessing the risk of $S$. aureus intoxication is the number of $s e$ genes carried by one strain. As shown by relevant studies and SFP outbreaks, it is quite common for more than one se gene to be detected in $S$. aureus strains implicated in intoxication cases (see e.g., Hennekinne et al., 2009 [sea, sed, sej]; Kitamoto et al., 2009 [sea, sed]; Schmid et al., 2009 [sea, sed]; and Johler et al., 2015 [sea, sed] in Table 1). One of the most recent examples is an outbreak documented by Johler et al. (2015), which occurred in a Swiss boarding school and affected 14 individuals. The $S$. aureus strain identified as the source of that outbreak harbored both sea and sed. Likewise, both SEA and SED were recovered from the implicated food (soft cheese) at levels of $>6 \mathrm{ng} / \mathrm{g}$ cheese and $>200 \mathrm{ng} / \mathrm{g}$ cheese, respectively. Since SEA and SED production are regulated by different mechanisms, it is evident that more 
information is needed on how these mechanisms are triggered in different food environments.

Identifying the point of entry of the $S$. aureus strain into the food chain and the clonal lineage to which it belongs will provide information that could be used in risk assessment profiles for identification of relevant preventive controls. A recent study by Kümmel et al. (2016) provides insight in this matter. Through the collection of samples from cow to retail product (ripened semi-hard cheese) at 18 dairy farms, the authors found that the bovine udder constitutes an important source of $S$. aureus in the dairy industry. Strains of genotype B were those most successfully transmitted from cows into the dairy production chain. The strain implicated in the outbreak at the Swiss boarding school was also assigned to an S. aureus of genotype B (Johler et al., 2015). Similarly, the study by Hummerjohann et al. (2014) showed that genotype B strains are primarily found in semi-hard cheeses produced from raw milk.

It should be borne in mind that pathogenic bacteria evolve with consumers' changing habits and the development of food production methods, and that microbial risk assessment should also develop in a similar manner. A typical example of studies in this direction is the one assessing the impact of temperature fluctuations in toxin production of $S$. aureus in deli meals (Røssvoll et al., 2014). Moreover, the recognition that bacterial responses are the result of a complex network of genetic events should direct research efforts toward a better understanding of these mechanisms, with the aim of more efficient pathogen control throughout the food production chain.

\section{CONCLUDING REMARKS}

Staphylococcus aureus is a highly evolved pathogen that brings about a number of challenges to food production. The physiological properties of the bacterium as such pose the first challenge for SFP containment. S. aureus robustness for growth along with its natural niches assists in the establishment of the pathogen in a broad range of food products. Poor hygiene habits by food handlers further facilitate its entrance into the food chain. In addition, $S$. aureus is an evolutionary flexible pathogen. Horizontal gene transfer is one of the main ways this bacterium acquires virulence factors. Therefore, the continual changes in food habits and processing methods trigger the adaptation mechanisms of the pathogen. The latter has brought about

\section{REFERENCES}

Adams, M. R., Moss, M. O., and Mcclure, P. J. (2016). Bacterial Agents of Foodborne Illness - Staphylococcus aureus. Food Microbiology, 4th Edn. Cambridge: Royal Society of Chemistry.

Alibayov, B., Karamonova, L., Hollerova, R., Zdenkova, K., and Demnerova, K. (2015). Differences in transcription and expression of staphylococcal enterotoxin $C$ in processed meat products. LWT Food Sci. Technol. 64, 578-585. doi: 10.1016/j.lwt.2015. 06.026

Argudín, M. Á., Mendoza, M. C., and Rodicio, M. R. (2010). Food poisoning and Staphylococcus aureus enterotoxins. Toxins 2, 1751-1773. doi: 10.3390/ toxins 2071751 new strains exhibiting increased virulence and resistance to the applicable preservation methods. The variety of SEs produced by $S$. aureus and the complexity of their regulation and production must moreover be carefully considered. Food parameters can critically affect SE production and hence the virulence of $S$. aureus. Understanding the mechanisms behind the expression of an SE and how they can be influenced by for example the food composition, salt content, and $\mathrm{pH}$ constitutes the greatest of the challenge to overcome in the battle against SFP. To conclude, more targeted studies of different SE regulatory mechanisms in food will be the key to allow for improved understanding of SFP and to enable risk assessment. Finally, considering the exponential advances in the area of -omics disciplines, an ultimate challenge and emerging trend in food science is to integrate the molecular data underpinning the phenotypic responses of bacterial pathogens into predictive models and then into QMRA. This will enable our knowledge on the physiological response of pathogens, which may explain uncertain areas of their behavior (at least currently) to be expressed in quantitative terms and translated in explicit (numerical) terms of risk for used in proper decisions to guard food safety.

\section{AUTHOR CONTRIBUTIONS}

NZ designed this review, performed the literature study, prepared Table 1 and Figures 1, 2, and wrote the major part of the manuscript. SJ and JS prepared Table 2. SJ, PS, and JS contributed in writing and critical revision. All authors approved the final version of the manuscript. JS was the principal supervisor and responsible for manuscript preparation.

\section{FUNDING}

This work was supported by the Swedish Research Council for Environment, Agricultural Sciences and Spatial Planning (FORMAS).

\section{ACKNOWLEDGMENTS}

The authors would like to acknowledge Henna-Maria Sihto for her input regarding regulatory mechanisms.

Asao, T., Kumeda, Y., Kawai, T., Shibata, T., Oda, H., Haruki, K., et al. (2003). An extensive outbreak of staphylococcal food poisoning due to low-fat milk in Japan: estimation of enterotoxin A in the incriminated milk and powdered skim milk. Epidemiol. Infect. 130, 33-40. doi: 10.1017/s0950268802007951

Barber, M. A. (1914). Milk poisoning due to a type of Staphylococcus albus occurring in the udder of a healthy cow. Philipp. J. Sci. 9, 515-519.

Barker, G. C., and Goméz-Tomé, N. (2013). A risk assessment model for enterotoxigenic Staphylococcus aureus in pasteurized milk: a potential route to source-level inference. Risk Anal. 33, 249-269. doi: 10.1111/j.1539-6924.2011. 01667.x

Bayles, K. W., and Iandolo, J. J. (1989). Genetic and molecular analyses of the gene encoding staphylococcal enterotoxin D. J. Bacteriol. 171, 4799-4806. doi: 10.1128/jb.171.9.4799-4806.1989 
Becker, K., Friedrich, A. W., Lubritz, G., Weilert, M., Peters, G., and Von Eiff, C. (2003). Prevalence of genes encoding pyrogenic toxin superantigens and exfoliative toxins among strains of Staphylococcus aureus isolated from blood and nasal specimens. J. Clin. Microbiol. 41, 1434-1439. doi: 10.1128/jcm.41.4. 1434-1439.2003

Belay, N., and Rasooly, A. (2002). Staphylococcus aureus growth and enterotoxin A production in an anaerobic environment. J. Food Prot. 65, 199-204. doi: 10.4315/0362-028x-65.1.199

Betley, M. J., and Mekalanos, J. J. (1985). Staphylococcal enterotoxin A is encoded by phage. Science 229, 185-187. doi: 10.1126/science.3160112

Blevins, J. S., Beenken, K. E., Elasri, M. O., Hurlburt, B. K., and Smeltzer, M. S. (2002). Strain-dependent differences in the regulatory roles of sarA and agr in Staphylococcus aureus. Infect. Immun. 70, 470-480. doi: 10.1128/iai.70.2.470480.2002

Bone, F. J., Bogie, D., and Morgan-Jones, S. C. (1989). Staphylococcal food poisoning from sheep milk cheese. Epidemiol. Infect. 103, 449-458. doi: 10. 1017/s0950268800030855

Borneman, D. L., Ingham, S. C., and Ane, C. (2009). Predicting growth-no growth of Staphylococcus aureus on vacuum-packaged ready-to-eat meats. J. Food Prot. 72, 539-548. doi: 10.4315/0362-028x-72.3.539

Borst, D. W., and Betley, M. J. (1993). Mutations in the promoter spacer region and early transcribed region increase expression of staphylococcal enterotoxin A. Infect. Immun. 61, 5421-5425.

Borst, D. W., and Betley, M. J. (1994). Phage-associated differences in staphylococcal enterotoxin A gene (sea) expression correlate with sea allele class. Infect. Immun. 62, 113-118.

Cao, R., Zeaki, N., Wallin-Carlquist, N., Skandamis, P. N., Schelin, J., and Rådström, P. (2012). Elevated enterotoxin a expression and formation in Staphylococcus aureus and its association with prophage induction. Appl. Environ. Microbiol. 78, 4942-4948. doi: 10.1128/aem. 00803-12

Cassat, J., Dunman, P. M., Murphy, E., Projan, S. J., Beenken, K. E., Palm, K. J., et al. (2006). Transcriptional profiling of a Staphylococcus aureus clinical isolate and its isogenic agr and sarA mutants reveals global differences in comparison to the laboratory strain RN6390. Microbiology 152, 3075-3090. doi: 10.1099/mic. 0.29033-0

Castro, A., Santos, C., Meireles, H., Silva, J., and Teixeira, P. (2016). Food handlers as potential sources of dissemination of virulent strains of Staphylococcus aureus in the community. J. Infect. Public Health 9, 153-160. doi: 10.1016/j.jiph.2015. 08.001

CDC (1968). CDC. MMWR Morb. Mortal. Wkly. Rep. 17, 109-110.

CDC (1983). CDC. MMWR Morb. Mortal. Wkly. Rep. 32, 294-295.

CDC (1989). CDC. MMWR Morb. Mortal. Wkly. Rep. 38, 417-418.

CDC (1997). Summary of notifiable diseases, United States. Morb. Mortal. Wkly. Rep. 46, 1189-1191.

Cha, J. O., Lee, J. K., Jung, Y. H., Yoo, J. I., Park, Y. K., Kim, B. S., et al. (2006). Molecular analysis of Staphylococcus aureus isolates associated with staphylococcal food poisoning in South Korea. J. Appl. Microbiol. 101, 864-871. doi: 10.1111/j.1365-2672.2006.02957.x

Chien, Y., Manna, A. C., Projan, S. J., and Cheung, A. L. (1999). SarA, a global regulator of virulence determinants in Staphylococcus aureus, binds to a conserved motif essential for sar-dependent gene regulation. J. Biol. Chem. 274, 37169-37176. doi: 10.1074/jbc.274.52.37169

Compagnone-Post, P., Malyankar, U., and Khan, S. A. (1991). Role of host factors in the regulation of the enterotoxin B gene. J. Bacteriol. 173, 1827-1830. doi: 10.1128/jb.173.5.1827-1830.1991

Cretenet, M., Nouaille, S., Thouin, J., Rault, L., Stenz, L., Francois, P., et al. (2011). Staphylococcus aureus virulence and metabolism are dramatically affected by Lactococcus lactis in cheese matrix. Environ. Microbiol. Rep. 3, 340-351. doi: 10.1111/j.1758-2229.2010.00230.x

Dack, G. M., Cary, W. E., Woolpert, O., and Wiggers, H. (1930). An outbreak of food poisoning proved to be due to a yellow hemolytic staphylococcus. J. Prev. Med. 4, 167-175.

Deghorain, M., and Van Melderen, L. (2012). The Staphylococci phages family: an overview. Viruses 4, 3316-3335. doi: 10.3390/v4123316

Denison, G. A. (1936). Epidemiology and symptomatology of Staphylococcus food poisoning: a report of recent outbreaks. Am. J. Public Health Nations Health 26, 1168-1175. doi: 10.2105/ajph.26.12.1168
Derzelle, S., Dilasser, F., Duquenne, M., and Deperrois, V. (2009). Differential temporal expression of the staphylococcal enterotoxins genes during cell growth. Food Microbiol. 26, 896-904. doi: 10.1016/j.fm.2009.06.007

Ding, T., Yu, Y. Y., Hwang, C. A., Dong, Q. L., Chen, S. G., Ye, X. Q., et al. (2016). Modeling the effect of water activity, $\mathrm{pH}$, and temperature on the probability of enterotoxin a production by Staphylococcus aureus. J. Food Prot. 79, 148-152. doi: 10.4315/0362-028x.jfp-15-161

Do Carmo, L. S., Cummings, C., Linardi, V. R., Dias, R. S., De Souza, J. M., De Sena, M. J., et al. (2004). A case study of a massive staphylococcal food poisoning incident. Foodborne Pathog. Dis. 1, 241-246. doi: 10.1089/fpd.2004.1.241

Domenech, A., Hernandez, F. J., Orden, J. A., Goyache, J., Lopez, B., Suarez, G., et al. (1992). Effect of six organic acids on staphylococcal growth and enterotoxin production. Z. Lebensm. Unters. Forsch. 194, 124-128. doi: 10.1007/ bf01190181

ECDC (2005). Microbiological criteria for foodstuffs. Ec 2073. Off. J. Eur. Union L338, 1-26.

EFSA (2017). The European Union summary report on trends and sources of zoonoses, zoonotic agents and food-borne outbreaks in 2016. EFSA J. 15:5077.

Eisenberg, M. S., Gaarslev, K., Brown, W., Horwitz, M., and Hill, D. (1975). Staphylococcal food poisoning aboard a commercial aircraft. Lancet 2, 595-599. doi: 10.1016/s0140-6736(75)90183-x

Evenson, M. L., Hinds, M. W., Bernstein, R. S., and Bergdoll, M. S. (1988). Estimation of human dose of staphylococcal enterotoxin A from a large outbreak of staphylococcal food poisoning involving chocolate milk. Int. J. Food Microbiol. 7, 311-316. doi: 10.1016/0168-1605(88)90057-8

Fetsch, A., and Johler, S. (2018). Staphylococcus aureus as a foodborne pathogen. Curr. Clin. Microbiol. Rep. 5, 88-96. doi: 10.1007/s40588-018-0094-x

Fisher, E. L., Otto, M., and Cheung, G. Y. C. (2018). Basis of virulence in enterotoxin-mediated staphylococcal food poisoning. Front. Microbiol. 9:436. doi: $10.3389 /$ fmicb. 2018.00436

Fujikawa, H., and Morozumi, S. (2006). Modeling Staphylococcus aureus growth and enterotoxin production in milk. Food Microbiol. 23, 260-267. doi: 10.1016/ j.fm.2005.04.005

Genigeorgis, C. A. (1989). Present state of knowledge on staphylococcal intoxication. Int. J. Food Microbiol. 9, 327-360. doi: 10.1016/0168-1605(89) 90100-1

Goerke, C., Pantucek, R., Holtfreter, S., Schulte, B., Zink, M., Grumann, D., et al. (2009). Diversity of prophages in dominant Staphylococcus aureus clonal lineages. J. Bacteriol. 191, 3462-3468. doi: 10.1128/jb.01804-08

Gustafson, J., and Wilkinson, B. (2005). 13 - Staphylococcus aureus as a Food Pathogen: the Staphylococcal Enterotoxins and Stress Response Systems A2 - Griffiths, Mansel. Understanding Pathogen Behaviour. Sawston: Woodhead Publishing.

Hallis, B. A., Thurston, C. F., and Mason, J. R. (1991). Glucose control of staphylococcal enterotoxin A synthesis and location is mediated by cyclic AMP. FEMS Microbiol. Lett. 64, 247-251. doi: 10.1016/0378-1097(91)90604-9

Heidinger, J. C., Winter, C. K., and Cullor, J. S. (2009). Quantitative microbial risk assessment for Staphylococcus aureus and Staphylococcus enterotoxin A in raw milk. J. Food Prot. 72, 1641-1653. doi: 10.4315/0362-028x-72.8.1641

Hennekinne, J. A., Brun, V., De Buyser, M. L., Dupuis, A., Ostyn, A., and Dragacci, S. (2009). Innovative application of mass spectrometry for the characterization of staphylococcal enterotoxins involved in food poisoning outbreaks. Appl. Environ. Microbiol. 75, 882-884. doi: 10.1128/aem.01924-08

Hennekinne, J. A., De Buyser, M. L., and Dragacci, S. (2012). Staphylococcus aureus and its food poisoning toxins: characterization and outbreak investigation. FEMS Microbiol. Rev. 36, 815-836. doi: 10.1111/j.1574-6976.2011.00311.x

Hennekinne, J.-A., Ostyn, A., Guillier, F., Herbin, S., Prufer, A.-L., and Dragacci, S. (2010). How should staphylococcal food poisoning outbreaks be characterized? Toxins 2, 2106-2116. doi: 10.3390/toxins2082106

Hu, J., Lin, L., Chen, M., and Yan, W. (2018). Modeling for predicting the time to detection of staphylococcal enterotoxin a in cooked chicken product. Front. Microbiol. 9:1536. doi: 10.3389/fmicb.2018.01536

Hummerjohann, J., Naskova, J., Baumgartner, A., and Graber, H. U. (2014). Enterotoxin-producing Staphylococcus aureus genotype B as a major contaminant in Swiss raw milk cheese. J. Dairy Sci. 97, 1305-1312. doi: 10.3168/jds.2013-7643

Islam, M. A., Parveen, S., Rahman, M., Huq, M., Nabi, A., Khan, Z. U. M., et al. (2019). Occurrence and characterization of methicillin resistant Staphylococcus 
aureus in processed raw foods and ready-to-eat foods in an urban setting of a developing country. Front. Microbiol. 10:503. doi: 10.3389/fmicb.2019.00503

Jarvis, A. W., Lawrence, R. C., and Pritchard, G. G. (1975). Glucose repression of enterotoxins $\mathrm{A}, \mathrm{B}$ and $\mathrm{C}$ and other extracellular proteins in staphylococci in batch and continuous culture. J. Gen. Microbiol. 86, 75-87. doi: 10.1099/ 00221287-86-1-75

Johler, S., Weder, D., Bridy, C., Huguenin, M.-C., Robert, L., Hummerjohann, J., et al. (2015). Outbreak of staphylococcal food poisoning among children and staff at a Swiss boarding school due to soft cheese made from raw milk. J. Dairy Sci. 98, 2944-2948. doi: 10.3168/jds.2014-9123

Johnson, E. A., Nelson, J. H., and Johnson, M. (1990). Microbiological safety of cheese made from heat-treated milk, part II. Microbiology. J. Food Prot. 53, 519-540. doi: 10.4315/0362-028x-53.6.519

Kadariya, J., Smith, T. C., and Thapaliya, D. (2014). Staphylococcus aureus and staphylococcal food-borne disease: an ongoing challenge in public health. Biomed Res. Int. 2014:827965.

Kérouanton, A., Hennekinne, J. A., Letertre, C., Petit, L., Chesneau, O., Brisabois, A., et al. (2007). Characterization of Staphylococcus aureus strains associated with food poisoning outbreaks in France. Int. J. Food Microbiol. 115, 369-375. doi: 10.1016/j.ijfoodmicro.2006.10.050

Kim, H. J., Griffiths, M. W., Fazil, A. M., and Lammerding, A. M. (2009). Probabilistic risk model for staphylococcal intoxication from pork-based food dishes prepared in food service establishments in Korea. J. Food Prot. 72, 1897-1908. doi: 10.4315/0362-028x-72.9.1897

Kitamoto, M., Kito, K., Niimi, Y., Shoda, S., Takamura, A., Hiramatsu, T., et al. (2009). Food poisoning by Staphylococcus aureus at a university festival. Jpn. J. Infect. Dis. 62, 242-243.

Kümmel, J., Stessl, B., Gonano, M., Walcher, G., Bereuter, O., Fricker, M., et al. (2016). Staphylococcus aureus entrance into the dairy chain: tracking S. aureus from dairy cow to cheese. Front. Microbiol. 7:1603. doi: 10.3389/fmicb.2016. 01603

Kusch, K., Hanke, K., Holtfreter, S., Schmudde, M., Kohler, C., Erck, C., et al. (2011). The influence of SAERS and sigma(B) on the expression of superantigens in different Staphylococcus aureus isolates. Int. J. Med. Microbiol. 301, 488-499. doi: 10.1016/j.ijmm.2011.01.003

Lappo, A., Bjørndal, T., Fernández-Polanco, J., and Lem, A. (2015). Consumers' Concerns and External Drivers in Food Markets. Fisheries and Aquaculture Circular No. 1102.

Le Loir, Y., Baron, F., and Gautier, M. (2003). Staphylococcus aureus and food poisoning. Genet. Mol. Res. 2, 63-76.

Le Marc, Y., Valik, L., and Medvedova, A. (2009). Modelling the effect of the starter culture on the growth of Staphylococcus aureus in milk. Int. J. Food Microbiol. 129, 306-311. doi: 10.1016/j.ijfoodmicro.2008.12.015

Lindqvist, R., Sylvén, S., and Vagsholm, I. (2002). Quantitative microbial risk assessment exemplified by Staphylococcus aureus in unripened cheese made from raw milk. Int. J. Food Microbiol. 78, 155-170. doi: 10.1016/s0168-1605(02) 00237-4

Lis, E., Podkowik, M., Bystron, J., Stefaniak, T., and Bania, J. (2012). Temporal expression of staphylococcal enterotoxin $\mathrm{h}$ in comparison with accessory gene regulator-dependent and -independent enterotoxins. J. Food Prot. 75, 238-244. doi: 10.4315/0362-028x.jfp-11-336

Lupien, J. R. (2007). Prevention and control of food safety risks: the role of governments, food producers, marketers, and academia. Asia Pac. J. Clin. Nutr. 16(Suppl. 1), 74-79.

Marta, D., Wallin-Carlquist, N., Schelin, J., Borch, E., and Radstrom, P. (2011). Extended staphylococcal enterotoxin D expression in ham products. Food Microbiol. 28, 617-620. doi: 10.1016/j.fm.2010.11.013

Morris, C. A., Everall, P. H., and Conway, H. D. (1972). Food-poisoning due to staphylococcal-enterotoxin E. Lancet 2, 1375-1376. doi: 10.1016/s01406736(72)92830-9

Müller, A., Seinige, D., Jansen, W., Klein, G., Ehricht, R., Monecke, S., et al. (2016). Variety of antimicrobial resistances and virulence factors in Staphylococcus aureus isolates from meat products legally and illegally introduced to Germany. PLoS One 11:e0167864. doi: 10.1371/journal.pone.0167864

Nema, V., Agrawal, R., Kamboj, D. V., Goel, A. K., and Singh, L. (2007). Isolation and characterization of heat resistant enterotoxigenic Staphylococcus aureus from a food poisoning outbreak in Indian subcontinent. Int. J. Food Microbiol. 117, 29-35. doi: 10.1016/j.ijfoodmicro.2007.01.015
Oppenheim, A. B., Kobiler, O., Stavans, J., Court, D. L., and Adhya, S. (2005). Switches in bacteriophage lambda development. Annu. Rev. Genet. 39, 409-429. doi: 10.1146/annurev.genet.39.073003.113656

Ostyn, A., De Buyser, M. L., Guillier, F., Groult, J., Felix, B., Salah, S., et al. (2010). First evidence of a food poisoning outbreak due to staphylococcal enterotoxin type E, France, 2009. Euro Surveill. 15:19528.

Paulin, S., Horn, B., and Hudson, J. A. (2012). "Factors influencing staphylococcal enterotoxin production in dairy products," in MPI Technical Prepared for the Ministry for Primary Industries, Wellington.

Pereira, M. L., Do Carmo, L. S., Santos, E. J. D., Pereira, J. L., and Bergdoll, M. S. (1996). Enterotoxin H in staphylococcal food poisoning. J. Food Prot. 59, 559-561. doi: 10.4315/0362-028x-59.5.559

Pillsbury, A., Chiew, M., Bates, J., and Sheppeard, V. (2013). An outbreak of staphylococcal food poisoning in a commercially catered buffet. Commun. Dis. Intell. Q. Rep. 37, E144-E148.

Pinchuk, I. V., Beswick, E. J., and Reyes, V. E. (2010). Staphylococcal enterotoxins. Toxins 2, 2177-2197.

Poupel, O., Proux, C., Jagla, B., Msadek, T., and Dubrac, S. (2018). SpdC, a novel virulence factor, controls histidine kinase activity in Staphylococcus aureus. PLoS Pathog. 14:e1006917. doi: 10.1371/journal.ppat.1006917

Rajkovic, A. (2012). Incidence, growth and enterotoxin production of Staphylococcus aureus in insufficiently dried traditional beef ham "govedja pršuta" under different storage conditions. Food Control 27, 369-373. doi: 10.1016/j.foodcont.2012.03.028

Regassa, L. B., Couch, J. L., and Betley, M. J. (1991). Steady-state staphylococcal enterotoxin type $\mathrm{C}$ mRNA is affected by a product of the accessory gene regulator (agr) and by glucose. Infect. Immun. 59, 955-962.

Rodriguez-Lazaro, D., Oniciuc, E. A., Garcia, P. G., Gallego, D., FernandezNatal, I., Dominguez-Gil, M., et al. (2017). Detection and characterization of Staphylococcus aureus and methicillin-resistant $S$. aureus in foods confiscated in EU borders. Front. Microbiol. 8:1344. doi: 10.3389/fmicb.2017.01344

Rosengren, A., Fabricius, A., Guss, B., Sylven, S., and Lindqvist, R. (2010). Occurrence of foodborne pathogens and characterization of Staphylococcus aureus in cheese produced on farm-dairies. Int. J. Food Microbiol. 144, 263-269. doi: 10.1016/j.ijfoodmicro.2010.10.004

Rosengren, A., Lindblad, M., and Lindqvist, R. (2013). The effect of undissociated lactic acid on Staphylococcus aureus growth and enterotoxin A production. Int. J. Food Microbiol. 162, 159-166. doi: 10.1016/j.ijfoodmicro.2013.01.006

Røssvoll, E., Rønning, H. T., Granum, P. E., Møretrø, T., Hjerpekjøn, M. R., and Langsrud, S. (2014). Toxin production and growth of pathogens subjected to temperature fluctuations simulating consumer handling of cold cuts. Int. J. Food Microbiol. 185, 82-92. doi: 10.1016/j.ijfoodmicro.2014.05.020

Sabike, I. I., Fujikawa, H., Sakha, M. Z., and Edris, A. M. (2014). Production of Staphylococcus aureus enterotoxin a in raw milk at high temperatures. J. Food Prot. 77, 1612-1616. doi: 10.4315/0362-028x.jfp-13-527

Sato'o, Y., Hisatsune, J., Nagasako, Y., Ono, H. K., Omoe, K., and Sugai, M. (2015). Positive regulation of staphylococcal enterotoxin $\mathrm{H}$ by rot (repressor of toxin) protein and its importance in clonal complex 81 subtype 1 lineage-related food poisoning. Appl. Environ. Microbiol. 81, 7782-7790. doi: 10.1128/aem.01936-15

Scallan, E., Hoekstra, R. M., Angulo, F. J., Tauxe, R. V., Widdowson, M.-A., Roy, S. L., et al. (2011). Foodborne illness acquired in the United States-Major Pathogens. Emerg. Infect. Dis. 17, 7-15. doi: 10.3201/eid1701.p11101

Schelin, J., Susilo, Y. B., and Johler, S. (2017). Expression of staphylococcal enterotoxins under stress encountered during food production and preservation. Toxins 9:E401.

Schelin, J., Wallin-Carlquist, N., Thorup Cohn, M., Lindqvist, R., Barker, G. C., and Rådström, P. (2011). The formation of Staphylococcus aureus enterotoxin in food environments and advances in risk assessment. Virulence 2, 580-592.

Schmid, D., Fretz, R., Winter, P., Mann, M., Hoger, G., Stoger, A., et al. (2009). Outbreak of staphylococcal food intoxication after consumption of pasteurized milk products, June 2007, Austria. Wien. Klin. Wochenschr. 121, 125-131. doi: 10.1007/s00508-008-1132-0

Schmidt, K. A., Donegan, N. P., Kwan, W. A. Jr., and Cheung, A. (2004). Influences of sigmaB and agr on expression of staphylococcal enterotoxin B (seb) in Staphylococcus aureus. Can. J. Microbiol. 50, 351-360. doi: 10.1139/w04-017

Schubert, J., Podkowik, M., Bystron, J., and Bania, J. (2017). Production of staphylococcal enterotoxins D and R in milk and meat juice by Staphylococcus aureus strains. Foodborne Pathog. Dis. 14, 223-230. doi: 10.1089/fpd.2016.2210 
Sergelidis, D., and Angelidis, A. S. (2017). Methicillin-resistant Staphylococcus aureus: a controversial food-borne pathogen. Lett. Appl. Microbiol. 64, 409-418. doi: 10.1111/lam.12735

Sihto, H.-M., Budi Susilo, Y., Tasara, T., Rådström, P., Stephan, R., Schelin, J., et al. (2016a). Effect of sodium nitrite and regulatory mutations $\Delta$ agr, $\Delta$ sarA, and $\Delta$ sigB on the mRNA and protein levels of staphylococcal enterotoxin D. Food Control 65, 37-45. doi: 10.1016/j.foodcont.2016.01.007

Sihto, H.-M., Tasara, T., Stephan, R., and Johler, S. (2016b). Growth behavior and temporal enterotoxin D expression of Staphylococcus aureus strains under glucose and lactic acid stress. Food Control 62, 69-73. doi: 10.1016/j.foodcont. 2015.10.008

Sihto, H.-M., Tasara, T., Stephan, R., and Johler, S. (2015). Temporal expression of the staphylococcal enterotoxin $\mathrm{D}$ gene under $\mathrm{NaCl}$ stress conditions. FEMS Microbiol. Lett. 362:fnv024.

Smith, J. L., Bencivengo, M. M., Buchanan, R. L., and Kunsch, C. A. (1986). Enterotoxin A production in Staphylococcus aureus: inhibition by glucose. Arch. Microbiol. 144, 131-136. doi: 10.1007/bf00414722

Sospedra, I., Soriano, J. M., and Mañes, J. (2013). Enterotoxinomics: the omic sciences in the study of staphylococcal toxins analyzed in food matrices. Food Res. Int. 54, 1052-1060. doi: 10.1016/j.foodres.2013.03.002

Stewart, C. M., Cole, M. B., and Schaffner, D. W. (2003). Managing the risk of staphylococcal food poisoning from cream-filled baked goods to meet a food safety objective. J. Food Prot. 66, 1310-1325. doi: 10.4315/0362-028x-66.7. 1310

Sumby, P., and Waldor, M. K. (2003). Transcription of the toxin genes present within the Staphylococcal phage phiSa3ms is intimately linked with the phage's life cycle. J. Bacteriol. 185, 6841-6851. doi: 10.1128/jb.185.23.6841-6851.2003

Susilo, Y., Sihto, H.-M., Rådström, P., Stephan, R., Johler, S., and Schelin, J. (2017). Reduced enterotoxin D formation on boiled ham in Staphylococcus aureus $\Delta$ agr mutant. Toxins 9:E263. doi: 10.3390/toxins9090263

Taulo, S., Wetlesen, A., Abrahamsen, R., Kululanga, G., Mkakosya, R., and Grimason, A. (2008). Microbiological hazard identification and exposure assessment of food prepared and served in rural households of Lungwena, Malawi. Int. J. Food Microbiol. 125, 111-116. doi: 10.1016/j.ijfoodmicro.2008. 02.025

Thaikruea, L., Pataraarechachai, J., Savanpunyalert, P., and Naluponjiragul, U. (1995). An unusual outbreak of food poisoning. Southeast Asian J. Trop. Med. Public Health 26, 78-85.

Thieffry, D., and Thomas, R. (1995). Dynamical behaviour of biological regulatory networks-II. Immunity control in bacteriophage lambda. Bull. Math. Biol. 57, 277-297. doi: 10.1007/bf02460619

Tremaine, M. T., Brockman, D. K., and Betley, M. J. (1993). Staphylococcal enterotoxin A gene (sea) expression is not affected by the accessory gene regulator (agr). Infect. Immun. 61, 356-359.

Tseng, C. W., and Stewart, G. C. (2005). Rot repression of enterotoxin B expression in Staphylococcus aureus. J. Bacteriol. 187, 5301-5309. doi: 10.1128/jb.187.15. 5301-5309.2005

Tseng, C. W., Zhang, S., and Stewart, G. C. (2004). Accessory gene regulator control of staphyloccoccal enterotoxin D gene expression. J. Bacteriol. 186, 1793-1801. doi: 10.1128/jb.186.6.1793-1801.2004

Valero, A., Perez-Rodriguez, F., Carrasco, E., Fuentes-Alventosa, J. M., GarciaGimeno, R. M., and Zurera, G. (2009). Modelling the growth boundaries of Staphylococcus aureus: effect of temperature, $\mathrm{pH}$ and water activity. Int. J. Food Microbiol. 133, 186-194. doi: 10.1016/j.ijfoodmicro.2009.05.023

Valihrach, L., Alibayov, B., and Demnerova, K. (2013). Production of staphylococcal enterotoxin $\mathrm{C}$ in milk. Int. Dairy J. 30, 103-107. doi: 10.1016/j.idairyj.2013.01.003

Veras, J. F., Do Carmo, L. S., Tong, L. C., Shupp, J. W., Cummings, C., Dos Santos, D. A., et al. (2008). A study of the enterotoxigenicity of coagulase-negative and coagulase-positive staphylococcal isolates from food poisoning outbreaks in Minas Gerais, Brazil. Int. J. Infect. Dis. 12, 410-415. doi: 10.1016/j.ijid.2007. 09.018

Voyich, J. M., Vuong, C., Dewald, M., Nygaard, T. K., Kocianova, S., Griffith, S., et al. (2009). The SaeR/S gene regulatory system is essential for innate immune evasion by Staphylococcus aureus. J. Infect. Dis. 199, 1698-1706. doi: 10.1086/ 598967

Wallin-Carlquist, N., Cao, R., Marta, D., Da Silva, A. S., Schelin, J., and Radstrom, P. (2010a). Acetic acid increases the phage-encoded enterotoxin A expression in Staphylococcus aureus. BMC Microbiol. 10:147. doi: 10.1186/1471-2180-10-147

Wallin-Carlquist, N., Marta, D., Borch, E., and Radstrom, P. (2010b). Prolonged expression and production of Staphylococcus aureus enterotoxin A in processed pork meat. Int. J. Food Microbiol. 141(Suppl. 1), S69-S74.

Wang, W., Baloch, Z., Jiang, T., Zhang, C., Peng, Z., Li, F., et al. (2017). Enterotoxigenicity and antimicrobial resistance of Staphylococcus aureus isolated from retail food in China. Front. Microbiol. 8:2256. doi: 10.3389/fmicb. 2017.02256

Weinrick, B., Dunman, P. M., Mcaleese, F., Murphy, E., Projan, S. J., Fang, Y., et al. (2004). Effect of mild acid on gene expression in Staphylococcus aureus. J. Bacteriol. 186, 8407-8423. doi: 10.1128/jb.186.24.8407-8423.2004

WHO (2015). WHO Estimates of the Global Burden of Foodborne Diseases. Foodborne Diseases Burden Epidemiology Reference Group 2007-2015. Geneva: World Health Organization.

Wieneke, A. A., Roberts, D., and Gilbert, R. J. (1993). Staphylococcal food poisoning in the United Kingdom, 1969-90. Epidemiol. Infect. 110, 519-531. doi: $10.1017 / \mathrm{s} 0950268800050949$

Woolaway, M. C., Bartlett, C. L., Wieneke, A. A., Gilbert, R. J., Murrell, H. C., and Aureli, P. (1986). International outbreak of staphylococcal food poisoning caused by contaminated lasagne. J. Hyg. 96, 67-73. doi: 10.1017/ s0022172400062549

Wu, S., Huang, J., Wu, Q., Zhang, F., Zhang, J., Lei, T., et al. (2018). Prevalence and characterization of Staphylococcus aureus isolated from retail vegetables in China. Front. Microbiol. 9:1263. doi: 10.3389/fmicb.2018.01263

Wu, S., Huang, J., Zhang, F., Wu, Q., Zhang, J., Pang, R., et al. (2019). Prevalence and characterization of food-related methicillin-resistant Staphylococcus aureus (MRSA) in China. Front. Microbiol. 10:304. doi: 10.3389/fmicb.2019.00304

Zeaki, N., Budi Susilo, Y., Pregiel, A., Rådström, P., and Schelin, J. (2015a). Prophage-encoded staphylococcal enterotoxin a: regulation of production in Staphylococcus aureus strains representing different sea regions. Toxins 7, 5359-5376. doi: 10.3390/toxins7124889

Zeaki, N., Rådström, P., and Schelin, J. (2015b). Evaluation of potential effects of $\mathrm{NaCl}$ and sorbic acid on staphylococcal enterotoxin a formation. Microorganisms 3, 551-566. doi: 10.3390/microorganisms3030551

Zeaki, N., Cao, R., Skandamis, P. N., Rådström, P., and Schelin, J. (2014). Assessment of high and low enterotoxin A producing Staphylococcus aureus strains on pork sausage. Int. J. Food Microbiol. 182-183, 44-50. doi: 10.1016/ j.ijfoodmicro.2014.05.010

Zhang, S., Iandolo, J. J., and Stewart, G. C. (1998). The enterotoxin D plasmid of Staphylococcus aureus encodes a second enterotoxin determinant (sej). FEMS Microbiol. Lett. 168, 227-233. doi: 10.1016/s0378-1097(98)00423-6

Conflict of Interest Statement: The authors declare that the research was conducted in the absence of any commercial or financial relationships that could be construed as a potential conflict of interest.

Copyright (C) 2019 Zeaki, Johler, Skandamis and Schelin. This is an open-access article distributed under the terms of the Creative Commons Attribution License (CC BY). The use, distribution or reproduction in other forums is permitted, provided the original author(s) and the copyright owner(s) are credited and that the original publication in this journal is cited, in accordance with accepted academic practice. No use, distribution or reproduction is permitted which does not comply with these terms. 